\title{
ENDOVASCULAR TREATMENT OF A BASILAR ARTERY DISSECTING ANEURYSM
}

\author{
Cristiane Borges Patroclo', Paulo Puglia Jr', , Claudia da Costa Leite ${ }^{1,2}$, \\ Fabio luji Yamamoto,", Jovana Gobbi Marchesi Ciríaco', \\ Milberto Scaff', , Adriana Bastos Conforto ${ }^{1,2}$
}

\begin{abstract}
Basilar artery (BA) dissecting aneurysms pose difficulties to treatment because both bleeding and thrombosis can happen in the same patient, clinical course is unpredictable and high morbidity is usual. We report the case of a 37-year-old woman with a BA aneurysm probably caused by arterial dissection, presenting embolic and hemorrhagic complications. The aneurysm was submitted to endovascular treatment with stenting and coil embolization. Clinical and radiological results were excellent and no complications were observed, suggesting that BA stenting and coil embolization may be a safe and effective treatment for this condition.
\end{abstract}

KEY WORDS: basilar artery dissection aneurysm, endovascular treatment, stenting, coil embolization.

\begin{abstract}
Tratamento endovascular de aneurisma dissecante da artéria basilar
RESUMO - Aneurismas associados a dissecção da artéria basilar ( $A B)$ apresentam dificuldades terapêuticas, pois sangramentos e fenômenos trombóticos podem ocorrer no mesmo paciente, seu curso clínico é imprevisível e sua morbidade, alta. Relatamos o caso de uma paciente de 37 anos com aneurisma de artéria basilar provavelmente causado por dissecção arterial, apresentando-se com complicações hemorrágicas e embólicas. O aneurisma foi submetido a tratamento endovascular com colocação de "stent" e embolização com molas. Os resultados clínico e radiológico foram excelentes e nenhuma complicação foi observada, sugerindo que o tratamento dos aneurismas de AB dissecantes com colocação de "stent" e embolização com molas possa ser seguro e eficaz.
\end{abstract}

PALAVRAS-CHAVE: aneurismas associados a dissecção da artéria basilar, tratamento endovascular, embolização com molas, "stent".

Dissecting aneurysms represent up to $28 \%$ of aneurysmal abnormalities involving the intracranial vertebral artery (VA) and its branches. In contrast, basilar artery (BA) dissection seems to be rare ${ }^{1,2}$, presenting more frequently with brain stem ischemia and rarely with subarachnoid hemorrhag $\mathrm{e}^{3-6}$. This lesion carries significant mortality and morbidity. Fatal rebleeding may occur in $19 \%$ of BA dissecting aneurysms that present with subarachnoid hemorrhage ${ }^{1,6}$. In addition, bleeding may complicate BA dissections presenting initially with brain ischemia. The risk is greater within the first 24 hours and rebleeding is less likely to occur after 2 weeks. In some cases, the lesion may even show spontaneous regression.

Because of their rarity, the management of BA dissecting aneurysms is controversial and challenging, as illustrated by the case we report, the patient give informed consent for publication this case report.

\section{CASE}

A 37-year-old woman reported a sudden sensation in the occipital region described in her words as a "dilating vein in the head" seven days before being admitted. The sensation lasted for a few hours and was followed by nausea and right homonymous hemianopsia. She had a history of migraine without aura since adolescence and her sister had a myocardium infarct at the age of 22.

CT demonstrated an ischemic infarction in the left occipital lobe. Cerebrospinal fluid was xantochromic and analysis revealed 1200 red cells. MRI showed the previous lesions and a left cerebellar infarction (Fig 1). MRA revealed a severe stenosis followed by dilatation in the middle portion of the basilar artery. Digital subtraction angiography (DSA), ten days after the ictus, showed a BA focal severe stensosis followed by dilatation and tight stenosis, suggesting a BA aneurysm caused by spontaneous dissection (Fig 2). Other slight stenoses were present in the middle and distal portions of the BA. The patient was submitted to endovascular treatment with BA stenting and aneurysm coil embo-

Departments of Neurology and Radiology, Hospital das Clínicas, São Paulo University, São Paulo SP, Brazil: ${ }^{1} \mathrm{MD},{ }^{2} \mathrm{PhD}$.

Received 12 February 2007, received in final form 4 June 2007. Accepted 4 August 2007.

Dra. Cristiane Borges Patroclo - Department of Neurology / Hospital das Clínicas / São Paulo University - Avenida Dr. Enéas de Carvalho Aguiar 255 / 5084 - 05403-00o São Paulo SP - Brasil. E-mail: crispatroclo@yahoo.com.br 


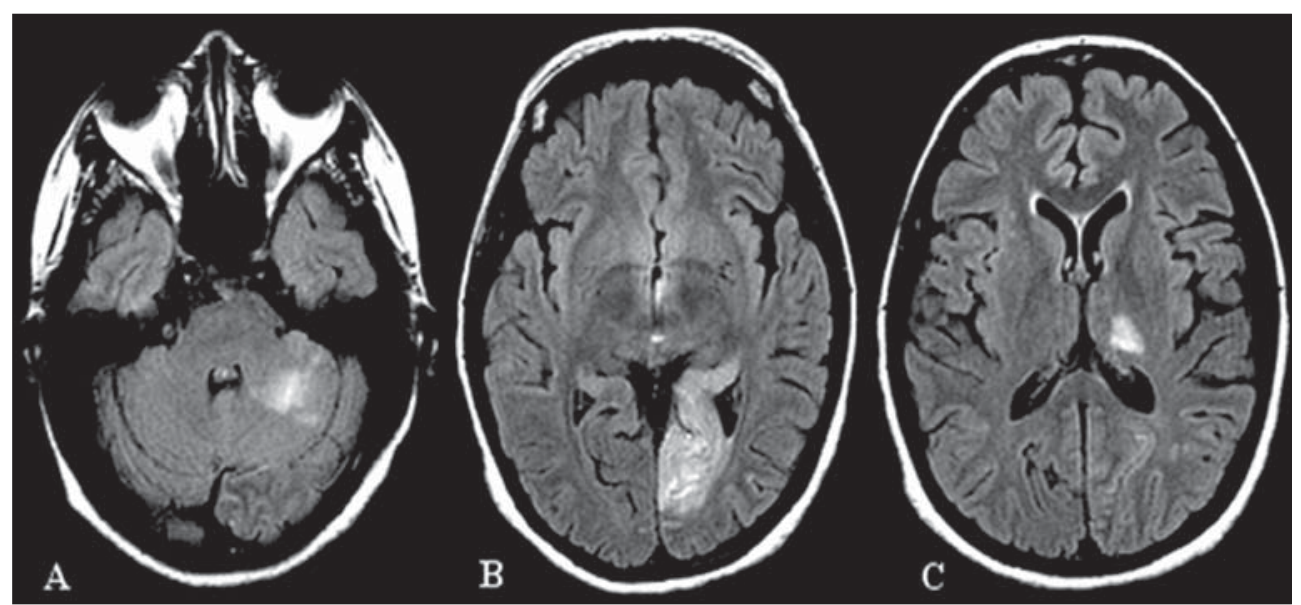

Fig 1. MRI (FLAIR image) shows infarcts in the left middle cerebellar peduncle and cerebellar hemisphere (A), occipital lobe (B) and thalamus (C).

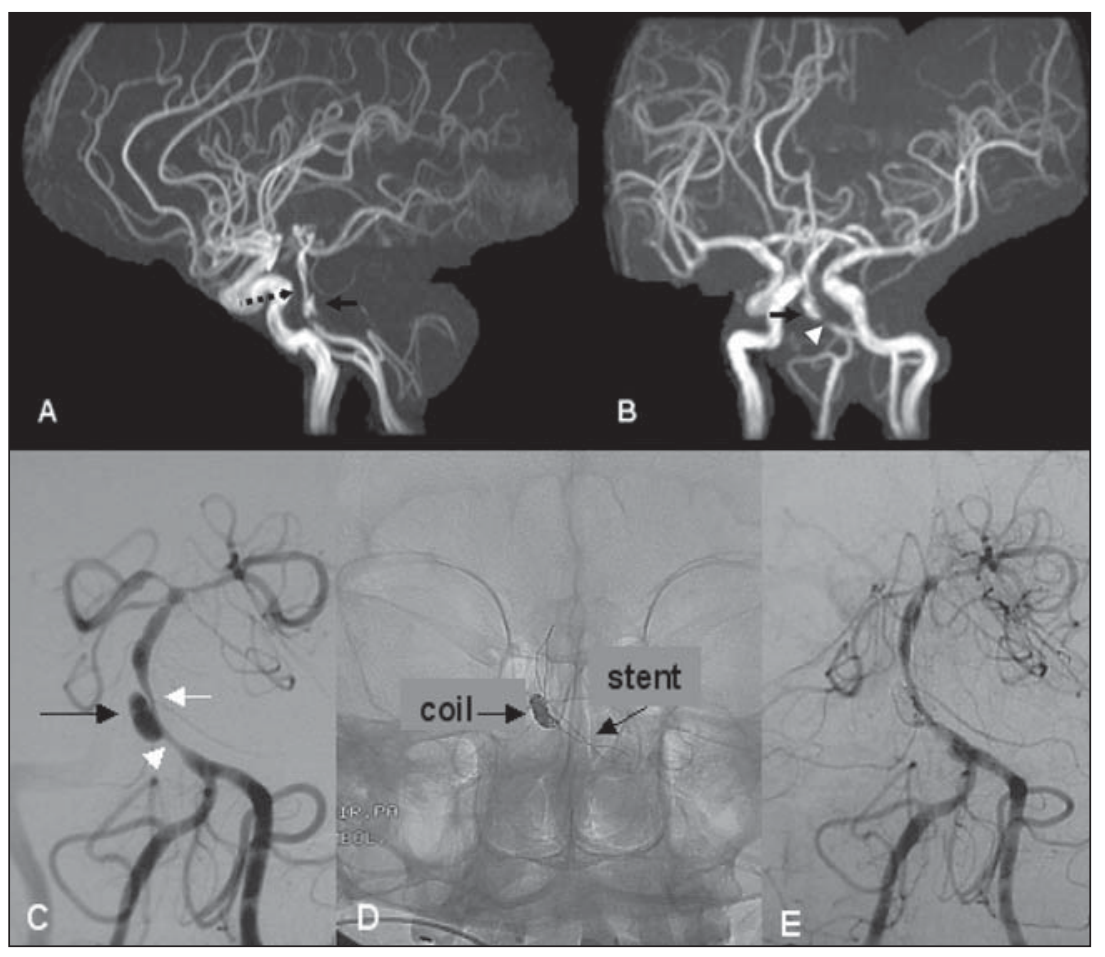

Fig 2. MRA $(A, B)$ and $D S A(C, D, E)$ shows proximal (white arrowhead, $B$ and $C$ ) and distal (black dotted arrow, $A$ and white arrow, C) focal stenosis and dilatation (black arrow; $A, B$ and $C$ ) in the middle portion of the basilar artery before endovascular treatment (C) with stenting and coiling (arrows, D). Good angiographical result after treatment $(E)$. lization without complications. During the procedure she received tirofiban, $0.6 \mathrm{mg}$ intra-arterial bolus and $6.6 \mathrm{mg}$ intravenous infusion for twelve hours. Afterwards, unfractioned heparin and clopidogrel $75 \mathrm{mg}$ qd were given for seven days and then heparin was substituted by aspirin 100 $\mathrm{mg}$ qd. One month later, clopidogrel was discontinued and aspirin dose was increased to $300 \mathrm{mg}$ qd.

The neurological examination remained was unchanged on discharge compared to patient admission. Two months later, no complications were observed. The NIH Stroke Score was 2 and the Modified Rankin score was 1. Six months later, DSA was repeated and showed the same good results. One a year after symptom onset, the the neurological examination is unchanged.

\section{DISCUSSION}

Three options should be considered when dealing with basilar artery aneurysms: conservative management, surgical treatment and endovascular intervention. The first one should be considered in patients with ischemic stroke without evidence of bleeding and without aneurysm formation. On the other hand, early intervention should be considered in patients with hemorrhage or aneurysms ${ }^{6}$. The three surgical options currently available are wrapping, proximal ligation and arterial reconstruction by direct surgical clipping. The efficacy of the first modality is un- 
proven, and there are only anecdotal descriptions of the other techniques in treatment of BA lesions. The poverty of information about surgical procedures can be justified by the difficult or sometimes impossible access to the BA. Endovascular approach of BA dissection relayed in the past on occlusion of the parent vesse ${ }^{6-8}$. Subsequently, the development of appropriate stents for intracranial arteries led to good results, first in $B A$ fusiform aneurysms unrelated to dissection $^{9}$ and later, in BA dissections ${ }^{10,11}$. Endovascular treatment of intracranial dissection aneurysms has been previously described. However, there has been limited experience on successful treatment of BA dissections complicated by aneurysms with stenting and coil embolization ${ }^{12-16}$. Good outcomes were reported after this procedure in only three cases ${ }^{9,13}$.

In the presented case, excellent angiographic and clinical results have been obtained. Endovascular treatment was chosen because of its potential advantages. First, a stent redirects blood flow by disrupting inflow into the aneurysm from the parent vessel. This decreased inflow contributes to thrombosis of the aneurysm and also probably reduces the risk of the coils becoming compacted. Second, a stent supports coiling by "remodeling" the neck of an aneurysm and by preventing migration of coil loops from aneurysms, especially from wide neck aneurysms that otherwise could represent an obstacle to treatment. Finally, a stent also provides a matrix for endothelial growth. The luminal surface of the stent is covered by a layer of neointima and the segment from which the aneurysm arises is thereby remodeled ${ }^{1,17-20}$. The approach to posterior circulation arteries by endovascular devices is quite direct and now there are available new, autoexpansible stents designed for intracranial use.

However, some cautions must be taken into account. First, stents may induce intimal hyperplasia and especially in smaller branches this could lead to significant stenosis. Second, as stents are potentially thrombogenic, anticoagulation during the procedure and long-term antiplatelet prophylaxis may be necessary and could represent an additional risk in the setting of subarachnoid hemorrhage. To avoid this risk, aneurysm access with a catheter to provide coil deployment was guaranteed before placing the stent. Third, in theory occlusion of ostia of small perforating branches, especially along the basilar trunk, could be complicated with ischemic events, although this has not been common in animal models ${ }^{13,18}$.

In conclusion, BA dissecting aneurysms pose dif- ficulties to treatment because both bleeding and thrombosis can happen in the same patient, clinical course is unpredictable and high morbidity is usual. No complications were observed in the presented case suggesting that BA stenting and coil embolization may be a safe and effective treatment for this condition.

\section{REFERENCES}

1. Ali MJ, Bendok BR, Tella MN, Chandler JP, Getch CC, Batjer HH. Arterial reconstruction by direct surgical clipping of a basilar artery dissecting aneurysm after failed vertebral artery occlusion: technical case report and literature review. Neurosurgery 2003:52:1475-1481.

2. Caplan LR. Caplan's stroke: a clinical approach. 3.Ed. Woburn, MA: Butterworth-Heinemann, 2000:295-342.

3. Hosoya T, Adachi M, Yamaguchi K, Haku T, Kayama T, Kato T. Clini$\mathrm{cal}$ and neuroradiological features of intracranial vertebrobasilar artery dissection. Stroke 1999;30:1083-1090.

4. Kai Y, Hamada J, Motohiro M, Yano S, Hamasaki K, Ushio Y. Successful treatment of a ruptured dissecting basilar artery aneurysm. J Neurosurg 2004;100:1072-1075.

5. Nakahara T, Satoh H, Mizoue T, Kawamoto H, Kohmo Y, Kurisu K. Dissecting aneurysm of basilar artery presenting with recurrent subarachnoid hemorrhage. Neurosurg Rev 1999;22:155-158.

6. Pozzati E, Andreoli A, Padovani R, Nuzzo G. Dissectimg aneurysms of the basilar artery: clinical study. Neurosurgery 1995;36:254-258.

7. Mizutani T, Aruga T, Kirino T, Yoshimasa M, Saito I, Tsuchida T. Recurrent subarachnoid hemorrhage from untreated rupture vertebrobasilar dissecting aneurysms. Neurossurgery 1995;36:905-913.

8. Yoshimoto Y, Katsumi H, Tanaka Y, Uchida T. Basilar artery dissection. J Neurosurg 2005;102:476-481.

9. Higashida T, Smith W, Gress D, et al. Intravascular stent and endovascular coil placement for a rupted fusiform aneurysm of the basilar artery. J Neurosurg 1997;87:944-949.

10. Malek AM, Higashida RT, Halbach VV, et al. Tandem intracranial stent deployment for treatment of an iatrogenic, flow limiting, basilar artery dissection: technical case report. Neurosurgery 1999:45:919-924.

11. Willing SJ, Skidmore F, Donaldson J, Nobo UL, Chernukha K. Treatment of acute intracranial vertebrobasilar dissection with angioplasty and stent placement: report of two cases. Am J Neuroradiol 2003;24:985-989.

12. Kaku Y, Yoshimura S, Yamakawa, Sakai N. Failure of stent-assisted endovascular treatment for rupted dissecting aneurysms of the basilar artery. Neuroradiology 2003;45:22-26.

13. Lanzino G, Wakhloo AK, Fessler R, Hartney ML, Guterman LR, Hopkins LN. Efficacy and current limitations of intravascular stents for intracranial internal carotid, vertebral, and basilar artery aneurysms. J Neurosurg 1999;91:538-549.

14. Lylyk P, Ceratto R, Hurvitz D, Basso A. Treatment of a vertebral aneurysm with stents and coils: technical case report. Neurossurgery 1998; 43:385-388.

15. Uhl E, Schmid-Elsaesser R, Steiger J. Rupted intracranial dissecting aneurysms: management considerations with a focus on surgical and endovascular techniques to preserve arterial continuity. Acta Neurochir (Wien) 2003;145:1073-1084.

16. Weber W, Hemkes H, Kuhne. Endovascular treatment of intracranial aneurysms facilitated by stent deployment to the basilar artery. Nervearzt 2000;71:843-848.

17. Sekhon LHS, Morgan MK, Sorby W, Grinnell V. Combined endovascular stent implantation and endovascular coil placement for the treatment of a wide-necked vertebral artery aneurysm: technical case report. Neurosurgery 1998;43:380-383.

18. Wakhloo AK, Lanzino G, Baruch BL, Hopkins LN. Stents for intracranial aneurysms: the beginning of a new endovascular era?. Neurossurgery 1998;43:377-379.

19. Andrade GC, Oliveira JG, Dauar RFB, Nalli DR, Braga FM. Aneurisma dissecante de artéria vertebral intracraniana fenestrada submetido ao tratamento endovascular: relato de caso. Arq Neuropsiquiatr 2005; 63: 352-356.

20. Iihara K, Sakai N, Murao K, et al. Dissecting aneurysms of the vertebral artery: a management strategy. J Neurosurg 2002;97:259-267. 